\title{
Social Consequence of Information and Communication, Technologies and the European Union : Policy Links
}

\author{
Vasileios Laopodis \\ Chairman \\ innopolis.org/cogniterra.org \\ Formerly European Comission DG Information Society and Media \\ vasileios.laopodis@gmail.com
}

\begin{abstract}
The issue of social consequences of Information and Communication Technologies has always been at the top of not only the political but also research and innovation agenda of the European Union. The move towards a European Information Society has placed severe demands on the adaptability of those concerned to economic and social changes while analysing and mitigating any adverse consequences and to avoid the emergence of a two-tier society and face moral and ethical challenges. Several initiatives have been launched by EU institutions and the Commission in particular to prepare the road towards a European Information Society. This paper first discusses EU initiatives from a research and innovation policy point of view and in particular RTD and deployment programmes such as IST, eTEN, eContent. It then analyses the need for designing and implementing a policy initiative at European Union level for promoting the positive impact of Information Society funded RTD and deployment results on other EU policies as diverse as environment, transport, public health, and establishing a permanent framework for linking information society to other EU policies and the so-called Brussels microcosm of EU policy makers. Finally it presents the "Information Society policy Link" initiative and in particular its first year results and policy implications on other social responsibility aspects for employers, employees and the State.
\end{abstract}

Keywords: ICT, Information Society, social impact, EU policies, Policy Links, Information Society Policy Links 


\section{Instead of introduction: Extract from a EC publication on the road towards an Information Society}

The last decades are witnessing the forging of a link of unprecedented magnitude and significance between the technological innovation process and economic and social organization. Countless innovations are combining to bring about a major upheaval in the organization of activities and relationships within society. A new "information society" is emerging in which the services provided by information and communications technologies (ICTs) underpin human activities. It constitutes an upheaval but can also offer new job prospects.

With easier access to information, it is becoming increasingly easy to identify, evaluate and compete with economic activities in all sectors. The pressure of the marketplace is spreading and growing, obliging businesses to exploit every opportunity available to increase productivity and efficiency. Structural adaptability is becoming a major prerequisite for economic success. The growing interconnection of the economy is leading to major productivity improvements in the production of goods but also in relation to services, and the borderline between goods and services is becoming increasingly blurred.

The economic impact of technological progress on growth and employment depends on the innovation process, which has become interactive. The linear model of innovation, with the innovative act being isolated, has in today's world been replaced by complex mechanisms: innovation requires constant and organized interdependence between the upstream phases linked to technology, and the downstream phases linked to the market.

The means available to create, process, access and transfer information are remodeling relationships in our societies. One of the most important aspects of current developments is the breathtaking expansion in the means available to us to communicate and process information (sound, text, images) in digital form.

Companies' operations have become unthinkable without the use of ICTs. These technologies are enabling them to seek total integration of their own functions in space and time and in terms of their environment. The introduction of ICTs, globalization and international competition are forcing companies to rethink the way in which they organize their production. Where the general public is concerned, the penetration of ICT-dependent products and services into everyday activities is also striking. This generates new forms of economic and social organization the structure of which is no longer subject to geographical constraints but depends on telecommunications networks or teleports: teleworking is emerging as a major social phenomenon. Authorities concerned with the management of public funds and wishing to provide their constituents with better quality services also call upon ICTs. Relationships between the general public and the authorities are changing, and more fundamentally the present boundaries between the role of the State and the market are altering. 
Despite the undeniable progress that has been made, the penetration of ICTs is not an unmitigated success story.

\section{Real Introduction: From ITA (Information Technology Assessment) to i2010 and more}

\section{Jacques, me and friends: some personal memories}

I first met Jacques Berleur in 1992 when I was in charge of the Luxembourg managed VALUE II programme (as part of the 2nd EU Framework RTD Programme) and in particular its Interfaces between Scientific Community, Research and Society. I was investigating about the state of play and actors in Europe regarding Social Consequences and ICT and Technology in general. Colleagues recommended touching base with an Informatics' professor in FUNDP University in Namur, Belgium. I then met a person that really influenced the rest of my life! Not only did I discover through Jacques the Information Technology Assessment (ITA) concept and collect precious information in social impact of computing, but it was the beginning of a lasting relationship with the IFIP world (TC9, WG9.2, SIG9.2.2), papers, international events etc. and a nice friendship with Jacques that still lasts!

Therefore it was for me an immense pleasure and also a privilege to accept to contribute to this book, and deliver some of the experience gained during these years with IFIP and the European Commission. I left the Commission in March 2006 to continue my activities in the not-for-profit sector by creating InnoPolis.org, and Europe of Cultures Forum: Adriatic \& Ionian Chapter and mentoring CogniTerra.org

\section{Towards an Information Society?}

J. Berleur in "Perspectives and Policies on ICT in Society" (Berleur and Avgerou, 2005) distinguishes two different periods: 1st period: 1994-1999 and 2nd period: From 1999 and beyond. He expresses some critisms regarding the orientation decided by the European Council and Parliament.

Regarding European policies and their impact at large: “...the effort the EU has to make on its communication should practise in two dimensions: a) A more explicit and transparent communication on the forces and weaknesses of Europe and European policies and b) A less institutional, formal, promotional communication than demonstrated by previous models of the last 35 years!...".

Regarding the Nature of the eEurope Initiative: "..........despite regretting some significant elements, this policy is above all a discourse that has to exist in order to pose a welcome European vision and challenge, and also.........the relevance of this policy will be shown at the local level, while on the other side it will have also to work for harmonious global development...."

In the next paragraphs we will try to analyse the real import and social consequences of EU policies related to Information Society. 


\section{From RTD results to policy making : the case of ICT}

\section{Policies and Activities}

Information and Communication Technologies (ICTs) are of crucial importance for Europeans. They are 'breakthrough technology', similar to the steam engine and electricity, that will have a major impact on how we live and work over the next century. They are therefore fundamental to achieving the EU's 'Lisbon goal' of greater economic growth, sustainable development and social cohesion. Consequently, the European Union devotes considerable effort to Information Society related actions (VL HCC7).

A range of policies / activities also aim to ensure that Europe exploits the possibilities offered by the Information Society and to soften any expected social consequences. In the next paragraphs we will try to discuss the social impact of ICT related research on EU policies. It is therefore necessary to oversee the policy areas. Currently there exist 31 different EU policies (see table 1).

\begin{tabular}{|l|l|l|}
\hline Agriculture & Employment and Social & Humanitarian aid \\
Audiovisual and Media & Affairs & Human rights \\
Budget & Energy & Information Society \\
Competition & Enlargement & Institutional affairs \\
Consumers & Enterprise & Internal Market \\
Culture & Environment & Justice, freedom and \\
Customs & External Relations & security \\
Development & External Trade & Public Health \\
Economic and Monetary & Food Safety & Regional Policy \\
Affairs & Foreign and Security & Research and Innovation \\
Education, Training, & Policy & Taxation \\
Youth & Fraud & Transport \\
& & \\
\hline
\end{tabular}

\section{Table 1}

Among these policy areas Information Society (and lately Audiovisual and Media policy) constitute an important priority for EU action. Under this umbrella we find the following areas (for detailed information on these priorities see IS Portal): [1]: Telecom Policies cover a large spectrum of issues and activities and produces policy proposals : From Spam to .eu and reduction of roaming tariffs to stimulating the ICT sector: eEurope2005; i2010 and RTD and Deployment programmes.

\section{Stimulating the Sector - eEurope 2005}

Policy priorities to stimulate the sector include promoting the development of the underlying infrastructure: Broadband and Security; stimulating the supply of advanced services, notably via the public sector: eGovernment, eHealth and eLearning, as well as Digital Rights Management; promoting the uptake of eBusiness, building on policies such as the eu domain - a key element in translating the European Single Market into the worlds of eBusiness. 


\section{Stimulating the Sector - i2010}

The focus of main action 2005+ includes the completion of a Single European Information Space which promotes an open and competitive internal market for information society and media; strengthening Innovation and Investment in ICT research to promote growth and more and better jobs; achieving an Inclusive European Information Society that promotes growth and jobs in a manner that is consistent with sustainable development and that prioritises better public services and quality of life.

\section{RTD and Deployment}

Research and Technological Development on ICT has been made possible via the Information Society Technologies Programme. The IST research programme [1] has been the largest thematic priority in the EU's Fifth (1998-2002) and Sixth (20022006) Framework Research Programmes. Together they represent an investment of over $€ 7 \mathrm{bn}$ in IST research, and are complemented by programmes such as eContent $(€ 100 \mathrm{~m})$ and eTEN $(€ 315 \mathrm{~m})$, which focus on digital content and eServices deployment respectively.

\section{Deployment of ICT: eContentPlus AND eTEN; Internet Content \& Services}

These activities promote the deployment of ICT related results and they are split in programmes such as: eContent $(€ 100 \mathrm{~m})$ and its successor eContent + , eTEN $(€ 315 \mathrm{~m})$ and also Content \& Services addressing the Public Sector Information Directive; Europe and Digitisation: the Lund Principles and Action Plan.

eContent and eTen in their new form will be an integral part of the already approved Competitiveness and Innovation Programme (CIP)to be coordinated by DG Enterprise and Industry.

\section{Exploiting the Benefits of the Information Society}

Anyone visiting the Commission policy priorities regarding ICT will discover action lines covering practically all aspects from eServices to the citizen (eGovernment, eHealth, eInclusion, eSafety/transport, Safer Internet Programme) and other application areas such as eLearning, eBusiness, ICT for Environment, Security cybercrime and Broadband communications. All of these EU ICT related policy initiatives and actions have prepared the road towards a European Information Society and increased the social responsibility for employers, employees and the State and in this way have important social consequences.

The issue of the social consequences of ICT has always been at the top of the research and innovation political and social agenda of the European Union. In the road towards a European Information Society severe demands have been placed on the adaptability of those concerned to economic and social changes. At the same time efforts have been deployed for analysing and mitigating any adverse 
consequences and to avoid the emergence of a two-tier society bringing moral and ethical challenges.

\section{Communication - dissemination issues}

The projects funded by these programmes offer benefits to all areas of Europe's economy and society. To fully realize these benefits, the technologies on the one hand, need to be linked closely to European policy-making in the relevant areas, and on the other ensure that the results are used as quickly as economically justifiable for the benefit of EU citizens and the EU economy. Effective communication is essential, both in transferring knowledge and influencing action ${ }^{\mathrm{i}}$.

On the other hand there is a need to ensure that the flow of R\&D funding is sustained by creating public appreciation of the benefits obtained. Such an action also demands effective communication to help recipients become aware about new technological breakthroughs facilitating our life but also about potential dangers and ways to prevent from any possible negative effects.

Passing the right message to the right people: For each of these objectives there is a need for a professional approach for a communication strategy. Such a strategy should analyse the target audiences and communication channels and it will define appropriate sub-objectives, communication messages, and techniques. In our view current efforts do not address these issues adequately.

The diverse nature of the $R \& D$ projects supported within the Framework Programmes means that different projects require different approaches. While some projects will produce results that are quickly obvious to end users in products or services, others will mainly affect industrial or commercial processes or components. Communication strategies need to take account of these differences and different target groups and stakeholders: networks, clusters and EU industrial groupings as well as the public.

Similarly, fostering public appreciation is not a task for which a single "one size fits all" approach should be expected. Different types of result are appropriate for different groups, and the diffusion of attitudes within a population operates differently both for different ideas and for different cultures. The existing state of public opinion is also a factor to be taken into account when devising strategies, and this will introduce inter-country differences.

We feel that applications of EU R\&D results, creating networks and leading to products and services that are in wide public use, represent an area in which strategies for uptake and strategies for public appreciation can overlap. This needs to be investigated to determine the full scale of the opportunity.

1 For the results of an analysis of particular characteristics related to communication and dissemination of RTD ICT see: Laopodis, V (2006) "Communicating Information Society Related RTD and Deployment Results in Support of EU Public Policies" in Social Informatics: An Information Society for all? In Remembrance of Rob Kling, Jacques Berleur, Markku I. Nurminen, and John Impagliazzo (2006) (eds). Proceedings of the Seventh International Conference on Human Choice and Computers (HCC7), IFIP TC9, Maribor, Slovenia, September 21-21, 2006. Springer Boston, Vol. 223/2006. 
There is scope for both direct promotion and influencing and for indirect action, allowing the message to become apparent through the actions of third parties. The underlying perception is that citizens who are alerted to the developments which the EU R\&D programmes are aiming at - and are delivering as time goes on - will be affected in three key ways:

- by coming to appreciate the case for EU R\&D

- by exerting market pull which speeds up the adoption of future developments

- by generating a constituency for the adoption of Framework Programme results by Commission policy departments.

\section{Information Society Policy Link}

\section{(ISPL)}

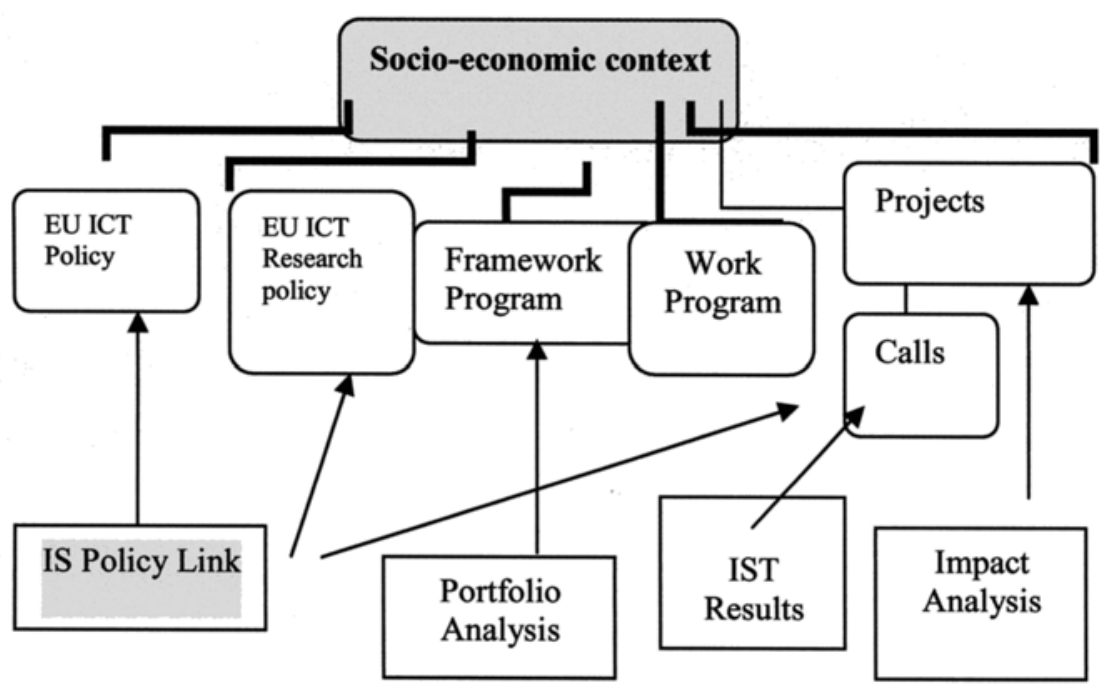

\section{Description of the initiative}

The Information Society promises potentially significant benefits throughout Europe's economy and society. These benefits will not be realized completely, however, if the technologies are not linked closely to European policymaking in the relevant areas. In the following diagram The IS Policy Link initiative is situated in the course of the RTD ICT programme trajectory.

Among the numerous EU awareness raising and promotion actions regarding ICT research and its impact the Information Society Policy Link initiative [3] of Information Society \& Media DG to identify and reinforce links between its projects 
and relevant EU policies launched in 2004, is linking Information Society projects with relevant European policies as diverse as environmental protection, security and public health [1].

Hence "Information Society Policy Link" where these cutting-edge projects are connected to the relevant policies, helping Europe both better implement today's policies and ensure that policy development takes the possibilities offered by ICTs into account.

This is a targeted initiative to EU Policy Makers started mid 2004 with the aim to improve co-operation between DG Information Society and Media and all other policy DGs, EU institutions as well as Public Administrations in Member States.

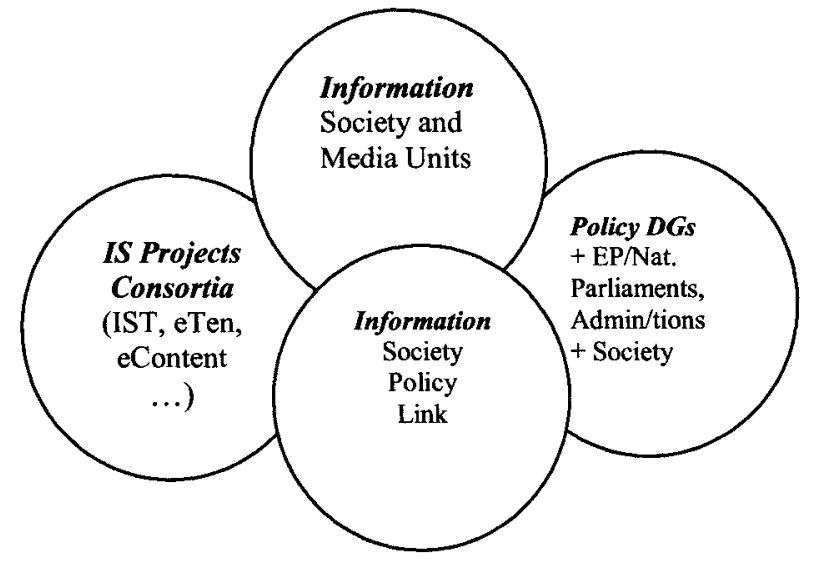

Fig.2 : The Information Society Policy Link multipartite collaboration

The approach selected is to proceed by linking project results from INFSOfunded actions (e.g. IST, eTen, eContent) to EU policy makers, thereby bringing together the major stakeholders. Its mission can be summarized as being a "Catalyst" and "broker service" function between INFSO and "partner" DGs/Services, other Institutions.

To attain its objectives the team had to first understand policy content by discussing with INFSO management, analysing information of $\sim 3.000$ projects from IST, eContent, eTEN and other actions, and identifying first promising cases per policy area and DG/EU service (in close cooperation with INFSO units). Then meetings with policy makers led to cooperation with a first group of pilot DGs in order to select Policy Cases for pilot DGs and investigate policy cases for others. In addition many networking actions have taken place (IST event, The Hague November 2004) which brought together stakeholders from six policy Digs, INFSO units and 25 project consortia.

The Figure 2 illustrates the multipartite collaboration where all main actors such as EU policy makers; INFSO Units; INFSO funded projects consortia (under programmes such as: Information Society Technology - IST, European Trans European Networks - eTEN, Digital Content (eContent and eContentplus) are 
involved with major beneficiaries EC policy DGs/services (main target), other EU institutions (in particular EP), Agencies National Parliaments and Member States administrations.

\section{Impact of ICT research projects on other $\mathrm{EU}$ policy areas}

The pilot phase of this initiative which ended in June 2005 identified $\sim 200$ Policy Cases (promising projects) grouped in six categories covering 20 European Union Policy Areas.

- European Society: Culture \& Multilingualism; Education; Employment \& Social Affairs; Health; E-Inclusion

- Governance: E-Government \& E-Democracy; Regional Policy; Security \& Justice; Sustainable Development; Environment; Energy \& Transport; Agriculture \& Fisheries

- Competitiveness: Enterprise Policy; Industrial Policy; Single Market

- Research \& Innovation: Information Society; Research \& Technology; Standardization

- International Relations: International Community; (External Trade, External Relations, Development, Humanitarian Aid)

To demonstrate the impact of DG Information Society and Media funded ICT research and development projects on specific EU public policies we discuss below the case of EU environmental policy where ICTs could be used for policy purposes.

\section{First Findings of pilot phase}

About 200 Policy Cases (promising projects) were identified and grouped in six categories covering 20 Policy Areas. Promotional material (published July 2005, onwards) includes a general leaflet (6-pages A4) on the Information Society Policy Link initiative and for each of the $\sim 20$ EU Policy Areas was one leaflet (6-page A4) on INFSO's contributions on, and links with the specific policy area, plus with 7-10 Fact Sheets corresponding to the selected Policy Cases.

The following table presents the outcome of the first phase of the project and in particular selected Success Stories/Policy cases impacting (a) EU Public Health policy and (b) EU Environment policy. For each policy case the following elements were indicated:

- Project Identification (name, EC code, webpage);

- Policy Area (policy domain e.g. air quality for environmental policy);

- Related policy measure (EU major programmes, references to EU Communications, Directives, Ministerial conferences proceedings etc.);

- Beneficiaries (in both EU and national/regional level);

- Expected impact (concrete impact on policy making or policy monitoring process). 


\section{Typical Case Stories/Success Stories}

The following cases have been identified regarding the EU Public Health policy

- EURODONOR: Sharing information on organ donation

- EUTIST-M: Closing the innovation gap in health

- HEARTS and MYHEART: Early warning of heart disease

- INFOGENMED and INFOBIOMED: Exploiting genomics for medicine

- MEDASHIP and OPTESS: Sailing towards tele-medicine

- NETC@RDS and NETC@RDS for eEHIC: Trans-European access to health services

- PICNIC: Defining the agenda for regional healthcare

- STEMNET: Connecting up stem cell donation

- The following cases have been identified regarding the EU Environment policy.

- APNEE-TU: Early warning of environmental hazards

- DISMAR: Open standards for marine risk management

- EGERIS: Joined up emergency response

- HARMONOISE: One voice on noise assessment

- HEAVEN: Controlling pollution through real time traffic management

- MINEO: Mitigating mining impacts

- ORCHESTRA: Risk management for Europe

- OSIRIS: Timely responses to flood risks

- SUMARE: Sustainable marine environments

- eSEVESO: Cost-effective compliance

\section{Information Society Policy Link: The next steps}

In order to better demonstrate the impact of IS projects and initiatives on other EU policy areas the instrument of Policy Interfaces and Policy Workshops have been launched in 2005. Policy Interfaces are structured meetings between Information Society and Media Directorate-General and other EU services with the aim to inform Policy DGs about INFSO plans for RTD activities in ICT, listen to their specific requirements for ICT research and ensure that results from INFSO-funded research projects and other activities can support the implementation of EU policies to the fullest possible extent.

Under this framework IS Policy Workshops i.e. a working event/conference on a particular theme are organized in cooperation with INFSO units, one or more thematic sub -groups or DGs.

First themes proposed are:

- Employability of ICT Professionals, Project: Indic@tor (FP5, IST-200032468)

- "What research findings say and how policy makers can exploit it", Brussels 26 April 2005

- Beyond the internet: MPs and communication, Project: EPRI, Slot in event for MEPs (23-24 May 2005) 
- E-resources for SMEs: Project: PROMIS (BSOLE (eTen)-GUIDE (eContent)-EASYTRADE (IST) Brussels (UEAPME) - 14 June 2005

- eInclusion / eUser workshops, October 2005; February 2006

- Competitiveness for SMEs: Project: Ecolead, DBE et al, May 12 2006:

The next phases of the Information Society Policy Link initiative will focus on three areas:

- Refinement of existing cases e.g. review existing data collections revisit findings (FP5); processing new information (mainly 1ST FP6; eTen; eContent); new wave of Policy Cases for each of 20 thematic areas

- Expansion of coverage by establishing contacts with remaining DGs and run Policy Interface meetings with DGs; launch special actions for EP, and pilot National Parliaments, MS Administrations

- Promotion and in particular disseminate first findings to EU policy makers; Targeted promotions campaign; Launch new publications on new Policy areas and cases; Organize a number of IS Policy Workshops; Pilot actions for MEP, National Parliaments and Administrations

Furthermore synergies will be sought between DG INFSO coordinated related information services and projects such as IST results and Information Society Policy Link and targeted promotional efforts to increase societal awareness on the impact of ICTs in economy and society.

\section{Conclusion}

The European Commission is supporting ICT research for the last 20 years with considerable resources devoted not only to IT technologies and communications but also to important applications notably in the areas of Public Health and Environment. Project results from the most recent Framework Programmes (FP4 and beyond) have demonstrated that even if selected on their policy relevance but mainly for its scientific merit, numerous ICT EU funded projects have considerable impact on other EU policies such as public health, environment, security, regional policy etc.

The first results of the DG Information Society and Media Information Society Policy Link initiative show that practically all policy areas could benefit from such project results in particular in integrating new concepts to coming policy initiatives, monitoring the implementation of existing regulation e.g. pollution levels, biometric controls etc. Communication and awareness raising actions should be reinforced in order to inform policy makers at all levels and influence the decision making process. 


\section{References}

Berleur J., Avgerou C. (eds), 2005; Perspective and Policies on ICT in Society, A TC9 Handbook, Springer Science and Business Media, series IFIP vol 179.

http://europa.eu.int/information_society,

IS Portal, Information on all policy initiatives and actions covering the Information Society and Media area.

http://istresults.cordis.lu/index.cfm,

IST Results, Information service promoting RTD results emanating from the IST programme.

http://europa.eu.int/information_society/activities/policy_link/index_en.htm, ISPL 